\title{
Métodos y problemas interpretativos en los estudios de cerámica utilitaria: los materiales cerámicos y sus limitaciones en el yacimiento de Revenga, Burgos (s. VI-XI)
}

\section{Methodological and interpretational concerns arising from the study of common earthenware: the limits of ceramic material at the site of Revenga (Burgos, Spain) (6-11 ${ }^{\text {th }}$ Centuries)}

\author{
Esther Travé Allepuz ${ }^{1}$ \\ M. Karen Álvaro Rueda ${ }^{2}$ \\ Guillem Domingo Ribas ${ }^{3}$ \\ Universidad de Barcelona
}

\section{RESUMEN}

A lo largo de los últimos años las excavaciones arqueológicas llevadas a cabo en el yacimiento de Revenga (Comunero de Revenga, Burgos) han permitido recuperar algunos materiales cerámicos de cronologías tardoantiguas y altomedievales. Dado su estado de conservación muy precario, el carácter utilitario de este tipo de producciones y las dificultades que aún hoy existen en el estudio de la cerámica común altomedieval, dichos materiales plantean algunos problemas interpretativos que hemos intentado resolver a partir de una caracterización petrográfica de los mismos. Los resultados obtenidos aportan nuevos datos muy significativos para el conocimiento de las comunidades del Alto Arlanza, permiten precisar las distintas fases de ocupación del asentamiento de Revenga y abren nuevas perspectivas para la investigación futura.

\section{SUMMARY}

Archaeological fieldwork at the site of Revenga (Comunero de Revenga, Burgos) allowed discovering in recent years some late antique and early medieval pottery sherds. Given their precarious state of preservation, the utilitarian character of these products and the still existing lacks of knowledge in this domain, the materials found introduce some interpretative problems. We attempted to solve some of these throughout the petrographic characterization of these vessels. According to the results obtained new significant data contributing to the knowledge of

${ }^{1}$ esther.trave@ub.edu / ORCID iD: https://orcid.org/00000002-6769-4487

${ }^{2}$ kalvaro@ub.edu / ORCID iD: https://orcid.org/0000-00031321-7260

3 gdominri7@alumnes.ub.edu / ORCID iD: https://orcid. org/0000-0002-7848-1321 peasant communities at the Upper Arlanza Basin are introduced, and a more precise occupation sequence at the site of Revenga is discussed, opening new perspectives for future research.

PALABRAS CLAVE: cerámica utilitaria; petrografía; muestreo; tecnología de producción; distribución.

KEY WORDS: utilitarian pottery; petrography; sampling; technology of production; distribution.

CÓMO CITAR ESTE ARTÍCULO / CITATION: Travé Allepuz, E., Álvaro Rueda, M. K. y Domingo Ribas, G. 2020: "Métodos y problemas interpretativos en los estudios de cerámica utilitaria: los materiales cerámicos y sus limitaciones en el yacimiento de Revenga, Burgos (s. VIXI)", Archivo Español de Arqueología 93, 229-247. https:// doi.org/10.3989/aespa.093.020.012

\section{INTRODUCCIÓN}

El territorio del Alto Arlanza, en las estribaciones meridionales de la Sierra de la Demanda y los Picos de Urbión constituye un espacio privilegiado para el estudio de las formas de poblamiento altomedieval y la organización del paisaje entre los siglos VI y XI. Este valle serrano acoge un número considerable de necrópolis rupestres presididas por edificios de culto en las que se advierten también los indicios de un hábitat cuyas características y estructura es necesario investigar (Fig. 1). Las intervenciones arqueológicas recientes en el yacimiento arqueológico de Revenga

Copyright: ( 2020 CSIC. Este es un artículo de acceso abierto distribuido bajo los términos de una licencia de uso y distribución Creative Commons Reconocimiento 4.0 Internacional (CC-by 4.0). 


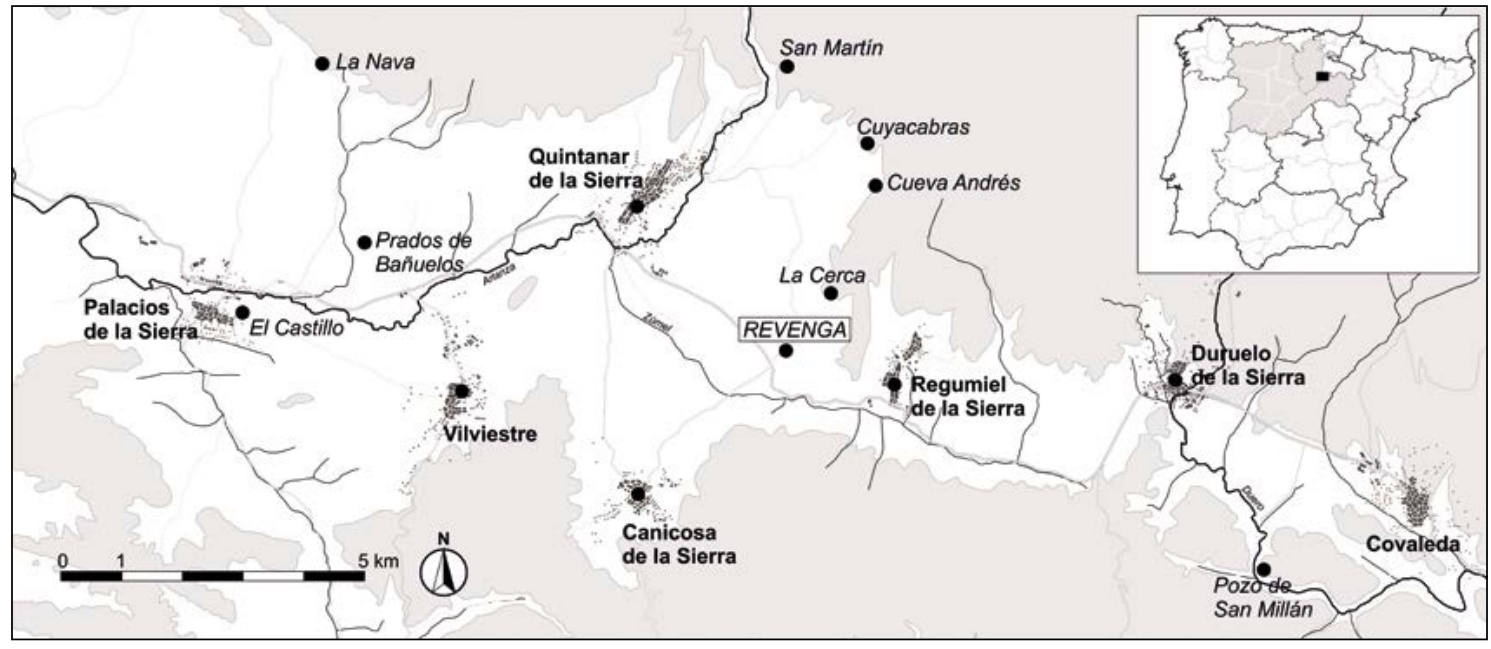

Figura 1. Localización del yacimiento de Revenga, entre las cabeceras de los ríos Arlanza y Duero (dibujo GRAMP.UB, sobre base cartográfica IGN).

(Comunero de Revenga, Burgos) han superado por primera vez la fragmentación del registro arqueológico y la visión parcial y limitada que ofrecen las necrópolis en favor de una interpretación global del asentamiento, teniendo en cuenta que este aglutina una iglesia con su cementerio circundante, pero también una nutrida representación de estructuras de hábitat con cimientos asentados sobre el suelo de arenisca (Álvaro et alii 2018a, 2018b). La excavación arqueológica y el estudio analítico de los materiales recuperados -fundamentalmente cerámicos y líticos- en un contexto bien definido, junto con la revisión y actualización del registro conocido en las otras necrópolis de la zona, han contribuido a incrementar el conocimiento que tenemos acerca de las formas de ocupación y articulación de este territorio de alta montaña entre los siglos VI-XI.

A pesar de los múltiples esfuerzos que se han hecho en los últimos años y que se están haciendo en la actualidad, el estudio de las producciones cerámicas utilitarias o comunes altomedievales no está en absoluto resuelto. Afortunadamente, los avances han sido especialmente significativos en varios aspectos. Por un lado, se ha incrementado el número de los volúmenes cerámicos estudiados y publicados, en parte gracias a una revisión y actualización de los análisis de materiales procedentes de la arqueología de gestión (Vigil-Escalera y Quirós 2016). Las críticas que en ocasiones se han hecho acerca del claro déficit relativo al estudio y publicación de los materiales procedentes de contextos arqueológicos excavados con carácter de urgencia parecen haber surtido los efectos oportunos, puesto que cada vez son más los conjuntos que se han dado a conocer. En buena medida, esto se debe a la integración de la arqueología de gestión en distintos proyectos de investigación relacionados con el conocimiento de las comunidades campesinas y de las formas de hábitat entre los siglos VI-IX (Quirós 2014: 144-145, 2017: 5; Roig 2009: 209).

Por otro lado, los criterios metodológicos para el análisis de las producciones tardoantiguas y altomedievales han contado con una renovación muy significativa, tanto en lo referente a las pautas de estudio de un yacimiento concreto, como en la necesaria explotación de datos desde una óptica territorial que tenga en cuenta la necesaria comparación de las distintas realidades regionales. Esto ha permitido dar a conocer algunas publicaciones de síntesis (Caballero et alii 2003; Vigil-Escalera y Quirós 2016) en las que se han llevado a cabo esfuerzos interpretativos y comparativos notables que han supuesto, ciertamente, una transformación sustancial del panorama conocido.

Los hallazgos recuperados en el yacimiento de Revenga deben contribuir al enriquecimiento del estado de la cuestión actual. Su caracterización es especialmente necesaria dado el carácter periférico de este espacio de montaña (Álvaro et alii 2018b; López et alii 2016a, 2016b), cuyos asentamientos parecen gestionarse de manera más o menos autónoma en relación con los poderes establecidos antes de su integración en las estructuras feudales del siglo XI, a partir de su incorporación en el Alfoz de Lara. Los trabajos de síntesis realizados hasta el momento carecen de hallazgos cerámicos procedentes de la zona de la Alta Sierra Pinariega, entre las cabeceras del Arlanza y el Duero, cuya producción y distribución parecen res- 
ponder a unos círculos regionales limitados, con una cierta complejidad interna y muy poco permeables a la influencia exterior.

Dado su estado de conservación muy precario, el carácter utilitario de este tipo de producciones y las dificultades que aún hoy existen en el estudio de la cerámica común altomedieval, dichos materiales plantean algunos problemas interpretativos que hemos intentado resolver a partir de la aplicación sistemática de un análisis macroscópico detallado de carácter morfológico y tecnológico que ha permitido la realización de un muestreo fiable para una caracterización petrográfica de estos materiales, cuyos resultados ofrecemos en este trabajo. Asimismo, pretendemos también poner sobre la mesa algunos elementos para la reflexión que puedan contribuir a refinar las estrategias metodológicas que se adoptan para abordar el análisis de este tipo de producciones, así como llamar la atención sobre sus limitaciones y los peligros de una sobre-interpretación en ocasiones excesiva basada únicamente en el examen visual macroscópico de los materiales. Con todo queremos contribuir de manera significativa a la generación de un conocimiento específico que nos permita profundizar en las sociedades que han fabricado y utilizado estas cerámicas y también en el diseño de unas pautas de análisis exportables y adaptables a las realidades de cada territorio, institución o equipo de investigación en función de las necesidades.

\section{CERÁMICAS COMUNES TARDOANTIGUAS Y ALTOMEDIEVALES EN EL NORTE Y CENTRO PENINSULAR: HACIA LA REGIONALIZACIÓN DE PRODUCCIONES}

Los principales estudios de cerámica común han puesto en relieve, a pesar de las numerosas diferencias y matices regionales, una transformación a distintos niveles en lo que se refiere a producción y distribución de productos cerámicos. El registro arqueológico y especialmente el estudio del material cerámico muestran a partir del siglo $\mathrm{V}$ una fuerte contracción de las escalas de producción, que adoptan patrones de carácter más local y circuitos de distribución más reducidos. Este fenómeno se interpreta habitualmente como resultado de una simplificación de la economía en su conjunto, lo cual implica un decrecimiento de la demanda aristocrática (Wickham 2009: 185). Este planteamiento de carácter general, surge del análisis comparado -imprescindible para el conocimiento de estas producciones- de una casuística repleta de singularidades que conocemos cada vez mejor en distintas zonas del norte y centro de la Península Ibérica.
En todos estos espacios, la incidencia desigual de los procesos de romanización, la realidad geográfica de los distintos asentamientos (a mayor o menor altitud, con una vinculación más o menos estrecha con los cursos fluviales y principales vías de comunicación) así como el papel que juegan las élites hispanorromanas del Bajo Imperio suponen condicionantes de carácter histórico que contribuyen a la diversidad de los contextos cerámicos. Pero debemos considerar también algunos factores de carácter científico vinculados fundamentalmente al número de yacimientos analizados y al volumen de materiales estudiados en cada yacimiento que condicionan también el carácter heterogéneo del estado actual de la cuestión. En definitiva, la realidad observada en el registro cerámico revela la existencia de unas transformaciones que se deben a factores sociales y humanos y que debemos explicar desde un punto de vista histórico, pero también cuenta con condicionantes científicos -básicamente relacionados con el muestreo, como veremoscuyo impacto debemos minimizar en la medida de las posibilidades.

Un territorio especialmente bien conocido, gracias a los trabajos de A. Vigil-Escalera (2004, 2006a), es el sur del sistema central y los alrededores de Madrid, para el que se han establecido algunas cronologías bastante precisas, en función de las cuales se interpreta que las producciones de terra sigillata hispánica tardía (TSHT) ya no acceden a los yacimientos madrileños a mediados del siglo $\mathrm{V}$, pero todavía lo hacen las derivadas de la sigillata provenzal (DSP), entre otras imitaciones locales. Hacia finales del primer cuarto del VI, los repertorios presentan aproximadamente una mitad de producciones de origen bajo imperial o de imitación junto con otra mitad constituida por pastas más gruesas, de facturas algo toscas, posiblemente a torneta (Vigil-Escalera 1999), con algunas variantes que aparecen o desaparecen entre los siglos VI-VIII en función de la cronología de los contextos analizados (Vigil-Escalera 2006a: 731). Las cerámicas a torno rápido, atribuidas a las producciones romanas o de tradición bajoimperial, habrían desaparecido casi por completo a partir de los siglos VII-VIII (VigilEscalera 2006a: 732), dando paso a un conjunto de producciones comunes, de tipo utilitario. Esta realidad se presenta casi sin variaciones para los materiales analizados en la vertiente norte del sistema central, representados a partir de las cerámicas de Cabeza de Navasangil (Tejerizo 2017: 95).

Esta relación entre el norte y el sur del Sistema Central nos permite adentrarnos en el repertorio cerámico de la Cuenca del Duero (Larrén et alii 2003). A grandes rasgos, se detecta la presencia de unas producciones que los autores denominan comunes imita- 
ción de sigillata y entre las que distinguen una fase temprana y otra avanzada, observando una evolución hacia las formas cerradas, globulares, y de pasta algo más gruesa (Larrén et alii 2003: 274-275). En este contexto territorial se hace mención de un horizonte de las necrópolis del Duero (Larrén et alii 2003: 280), cuya horquilla no se precisa con exactitud, pero que puede presentar un cierto paralelo con el entorno del Alto Arlanza, al menos en lo referente a los elementos funerarios.

Los trabajos posteriores en el ámbito del Duero han puesto en evidencia la necesidad de acotar algo más el marco territorial de un espacio heterogéneo $y$, a medida que han pasado los años y se ha avanzado en el conocimiento de estas producciones, se ha hecho de nuevo hincapié en la necesidad de aproximaciones en donde prime el carácter tecnológico del análisis por encima de las clasificaciones formales. De este modo, para la cuenca central del Duero se propone una desaparición de la TSHT también a mediados del siglo V (Tejerizo 2016: 247) en simultaneidad con una presencia cada vez mayor de producciones torneadas de modo lento. Los yacimientos analizados en los trabajos de síntesis para el Alto Duero, se sitúan todos ellos por debajo de la cota de 1000 m en contextos plenamente romanos, marcados por la presencia de villae (Bermejo 2011: 339), por lo que presentan algunas diferencias de calado respecto del territorio de Revenga cuyos resultados presentamos.

Aunque las cronologías manejadas en la zona de León son algo más tardías, en este espacio se observa una evolución desde unas producciones algo más decantadas, en las que predominan las ollas panzudas por encima de las ollitas o jarras con vertedera, a una producción local -las cerámicas denominadas grises leonesas- cuyo rasgo significativo es la cocción en atmósfera reductora (Gutiérrez y Miguel 2009). En suma, buena parte de los estudios analizan fundamentalmente el cambio en los modos de torneado, el incremento de inclusiones en las pastas, las atmósferas de cocción y, cuando es posible, la morfología para concluir que, a partir del siglo $\mathrm{V}$, tras la desaparición de las últimas producciones tardorromanas (TST, DSP) y el declive de las imitaciones, se generaliza un escenario en el que las producciones con marcado carácter local pasan a ser mayoritarias en la mayoría de regiones.

Llama la atención, desde luego, que todavía hoy las principales incertidumbres respecto de la cerámica tardoantigua y altomedieval parecen responder a determinadas carencias metodológicas que son difíciles de solventar en aproximaciones de carácter estrictamente macroscópico. De ahí la necesidad de diseñar verdaderas estrategias de análisis que permitan opti- mizar el potencial de estas cerámicas para el conocimiento de un periodo complejo. En territorios donde los trabajos de arqueometría tienen una trayectoria algo más dilatada, se insiste especialmente en la necesidad de clarificar el panorama relativo a las producciones comunes de carácter regional cuya asignatura pendiente es la definición del alcance territorial de este tipo de productos y la determinación de los parámetros cronológicos, al menos para los casos catalán y balear (Macías y Cau 2012: 527).

Las aproximaciones de carácter microscópico también se han llevado a cabo en el País Vasco, donde la clasificación del grupo de las producciones comunes deja de ser macroscópica para ganar en especificidad. Entre las cerámicas de esta zona se distinguen unas producciones gruesas manipuladas, entendidas como pastas desgrasadas cocidas a baja temperatura, en alternancia con las pastas oxidantes sin desgrasante añadido, ocasionalmente decantadas y cocidas a temperaturas algo superiores (Azkarate y Solaun 2016: 220). Esta caracterización de las pastas permite, sin duda, precisar con mayor detalle las distintas producciones analizadas y el eje principal de clasificación, a diferencia de otros contextos, deja de ser el sistema torneado sino los procesos de preparación de la pasta.

No parece procedente extendernos mucho más en el análisis de los territorios más alejados del área de estudio que nos ocupa, el Alto Arlanza, en ausencia de estudios analíticos que permitan precisar algo más en el estado de la cuestión conocido. Los trabajos realizados para Galicia y el norte de Portugal, Asturias, Cantabria, la Rioja, el Valle medio del Ebro, además de los ya expuestos, entre otros, han proporcionado una visión de conjunto suficientemente actualizada (Vigil-Escalera y Quirós 2016) que debe servir como punto de partida para caracterizaciones de carácter arqueométrico. El contexto general que reflejan todos estos estudios cerámicos es el de una simplificación progresiva de formas tendentes a los cuerpos esféricos o globulares y a unas pastas progresivamente más gruesas y poco depuradas. La dualidad entre el torneado rápido y lento parece una constante en la mayoría de trabajos, pero no todos coinciden -tampoco nosotros-con la sustitución generalizada del torno por la torneta.

En cualquier caso, disponer de todos estos elementos de análisis resulta fundamental a la hora de interpretar los datos a gran escala, necesariamente a partir de la comparación territorial. La existencia de una variabilidad regional fruto de la disgregación progresiva de la uniformidad romana y de la generación de un sistema socioeconómico nuevo es evidente, pero en dicha variabilidad entran también en juego elementos desvinculados de las interpretaciones estrictamente 
económicas. Algunos de estos elementos son el cambio de usos del material cerámico o la incorporación de otras materias primas como la madera para la satisfacción de necesidades cotidianas que a menudo habían cubierto los enseres de cerámica. Las transformaciones antropológicas y culturales derivadas de la desintegración del mundo romano implicarán también la aplicación de tecnologías de producción adecuadas a nuevas necesidades. Si estas tecnologías son más simples o más complejas que las de tiempos precedentes es un juicio de valor que deberíamos evitar.

Del mismo modo, un estudio lo más aséptico posible de las producciones altomedievales debería optar, al menos en la fase analítica, por calificativos meramente descriptivos (grueso o fino) evitando de nuevo la adjetivación que implica una comparación no exenta de prejuicios con el periodo anterior. Una definición de las cerámicas tardoantiguas o altomedievales y en concreto las producciones comunes de carácter regional como toscas o bastas implica que las anteriores romanas eran finas o cuidadas y, por lo tanto, mejores. En parte debido a prejuicios de este tipo, y en parte a causa de la propia invisibilidad que en ocasiones presenta el registro arqueológico (Vigil-Escalera 2006b), el conocimiento que tenemos de las producciones comunes es todavía deficitario. El estado de la cuestión actual necesariamente debe llevarnos a una exploración de las conexiones existentes a nivel regional (Macías y Cau 2012: 527) y entre los enclaves determinados y sus territorios circundantes, a partir de caracterizaciones precisas de los materiales y de análisis complejos de las realidades territoriales de los contextos. De ahí nuestro interés en contribuir al avance en el conocimiento de este tipo de producciones a partir del análisis microscópico de las cerámicas del Alto Arlanza en base a una estrategia sólida de muestreo que ya está en marcha en el yacimiento de Revenga, pero que debe ampliarse en el futuro.

\section{EL YACIMIENTO DE REVENGA Y SUS MATERIALES CERÁMICOS: ESTRATEGIAS METODOLÓGICAS Y CRITERIOS DE MUESTREO}

Los trabajos de excavación en el yacimiento de Revenga han revelado la existencia de un extenso espacio ocupado por estructuras de hábitat y de producción, cuyos restos quedan limitados en buena medida a las improntas sobre la roca y a una estratigrafía de escasa potencia (Álvaro et alii 2018a, 2018b). A pesar de ello, los trabajos de excavación han permitido recuperar los exiguos materiales presentes en el yacimiento con una asignación precisa vinculada a con- textos bien definidos, pese a su parquedad. Las estructuras residenciales se hallan diseminadas alrededor de un promontorio rocoso presidido por una pequeña iglesia rodeada por una extensa necrópolis de sepulturas rupestres, que durante muchos años había constituido el único elemento visible del yacimiento, aunque la prospección del entorno ya había permitido detectar los indicios del hábitat circundante (Padilla y Álvaro 2013: 14; López et alii 2016b).

El registro arqueológico de este espacio ha revelado hasta el momento una superposición de estructuras que se suceden en el asentamiento en distintos horizontes cronológicos en los que la apariencia general del poblado parece transformarse significativamente (Álvaro et alii 2018b). La ocupación más antigua del espacio, anterior al siglo VIII, se caracteriza por la presencia de estructuras circulares que aparecen distribuidas de manera más o menos uniforme en toda la superficie intervenida y pueden documentarse también sobre el promontorio rocoso con anterioridad a la delimitación del recinto sacro. Entre ellas se distinguen por su tamaño los tipos A $\left(3-4 \mathrm{~m}^{2}\right)$ y B $\left(5-8 \mathrm{~m}^{2}\right)$, siendo los más pequeños los anteriores. La transformación más significativa del poblado parece producirse al compás de la cristianización del asentamiento. La construcción de la iglesia y las primeras sepulturas antropomorfas que la rodean condicionarán a partir de este momento la ubicación de las viviendas, que quedarán algo más alejadas de este espacio central y que serán sustituidas por otras de planta cuadrada (Fig. 2); inicialmente, por unas estructuras de planta regular (Tipo C) y 11-18 $\mathrm{m}^{2}$ de superficie y, en las fases finales del asentamiento, por otras mayores (21-26 $\left.\mathrm{m}^{2}\right)$ y rectangulares (Tipo D) que, ocasionalmente constituyen ampliaciones de estructuras más antiguas de tipo C (Álvaro et alii 2018b: 385, 2018c: 7, fig. 4).

La ocupación del enclave es relativamente temprana a juzgar por los materiales cerámicos recuperados y las características generales del asentamiento. Las producciones más antiguas son especialmente abundantes, de cocción oxidante, tonos rosados, anaranjados y pajizos, pastas bastante finas y con una cronología relativa temprana, en relación con los conjuntos de estratos posteriores. También son habituales unas producciones de cocción reductora, de pastas finas, bizcochadas, cronológicamente posteriores a las primeras, y algunos individuos clasificables como 'cerámica gris altomedieval', algo mejor conocida (Gutiérrez y Bohigas 1989), de pastas gruesas y un repertorio formal reducido, con una cronología posterior al siglo VIII. Este conjunto mayoritario, lo completan algunos fragmentos de cerámica con vedrío; muy escasa y recuperada en los niveles más tardíos y de amortización, y algunos fragmentos muy aislados bruñidos, 


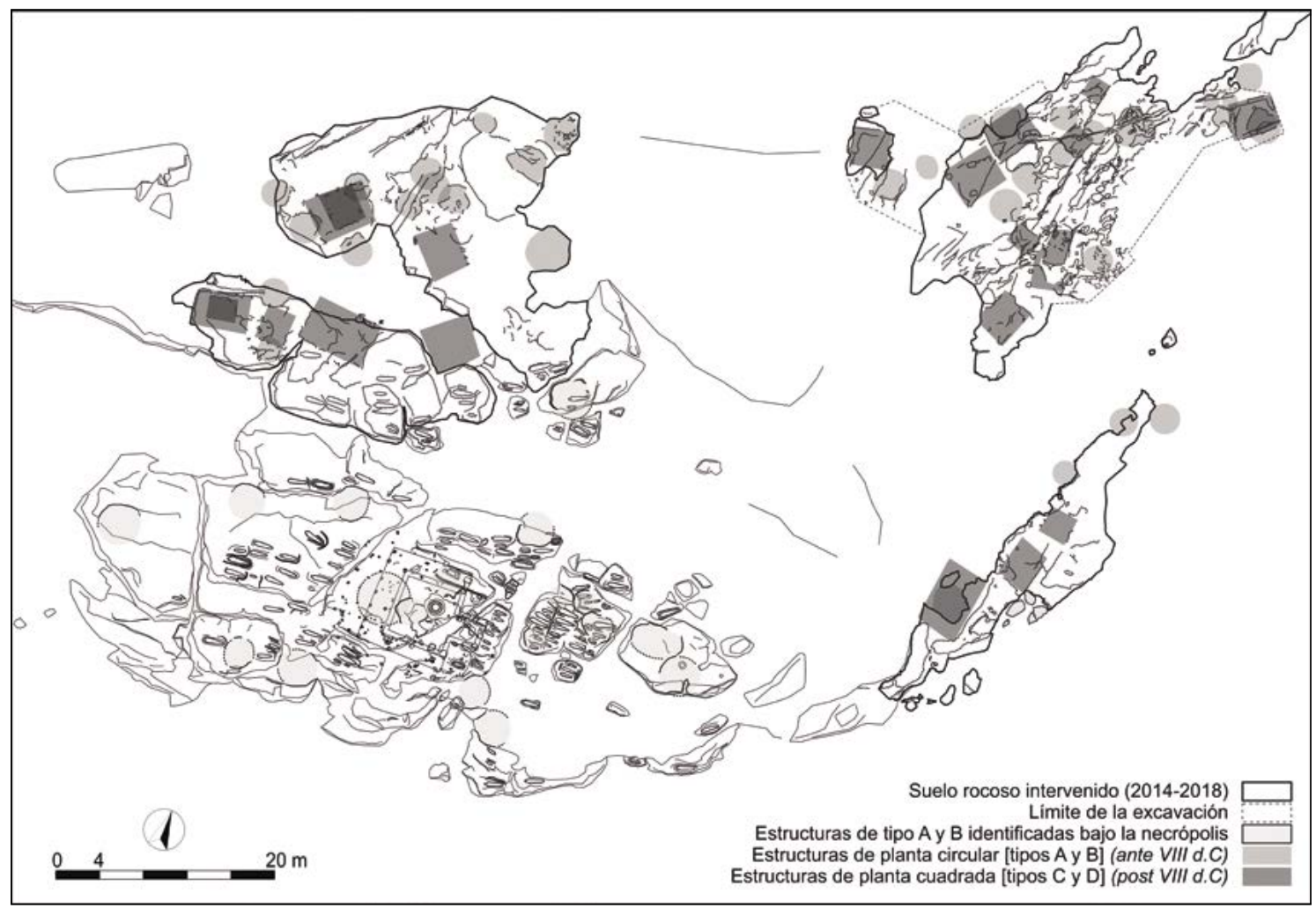

Figura 2. Planta general del yacimiento de Revenga, con la localización de la iglesia, la necrópolis y las principales estructuras de hábitat identificadas en función del tipo al que pertenecen (dibujo J. I Padilla y E. Travé).

pintados o espatulados, también de cronologías tempranas. La ocupación del asentamiento sin solución de continuidad y los procesos de reutilización, condicionan la escasez de los materiales. Las características de algunas producciones, especialmente las más antiguas, con pastas frecuentemente jabonosas, y el carácter algo abrasivo del suelo condicionan el rodamiento de los fragmentos y su estado de conservación.

En la mayoría de estos grupos, y de manera especial en los más antiguos, la presencia de algunas formas claramente identificables de cuencos y platos crateriformes o caliciformes (Fig. 3) nos permite aportar algunos paralelos que sustentan una propuesta cronológica que aboga por la presencia de poblamiento anterior al siglo VIII. Estas formas abiertas, que ya están presentes en la tradición indígena celtibérica (Burillo et alii 2009: 172-180), desaparecen por completo en el periodo altomedieval, siendo prácticamente imposible hallar paralelos de estas formas en época más tardía. Junto con estas formas singulares, se documentan para este periodo temprano, algunos bordes de jarra o redoma, orzas u ollas que son en absoluto extraños en el área del Duero (Larrén et alii 2003: 300) ni en la vertiente nordeste del Sistema Ibérico
(Hernández y Bienes 2003: 312). En ningún caso se ha detectado la presencia de cerámica romana o de imitaciones de ningún tipo (TSHT, DSP).

Considerando el panorama expuesto hasta ahora, parece evidente que el material cerámico de Revenga presenta algunas limitaciones como indicador cronológico para un periodo de poblamiento que estimamos largo, a juzgar por el registro arqueológico y la secuencia de transformación de las estructuras de hábitat. En ausencia -por ahora- de indicadores de datación absoluta como la radiocarbónica o la numismática, contar con conjuntos bien contextualizados y con la posibilidad de analizarlos desde un punto de vista tecnológico y funcional más que el estrictamente tipológico, aporta información valiosa desde el punto de vista de las transformaciones técnicas que operan en este tipo de cerámicas en un periodo de profundas transformaciones sociales. En consecuencia, nuestro planteamiento metodológico parte de la necesidad de superar la dicotomía aun existente entre los análisis macroscópicos y microscópicos; estos últimos aún muy insuficientes.

La base de nuestro muestreo parte de un estudio macroscópico previo realizado en base a dos premisas fundamentales: la primera es la no-selección de mate- 


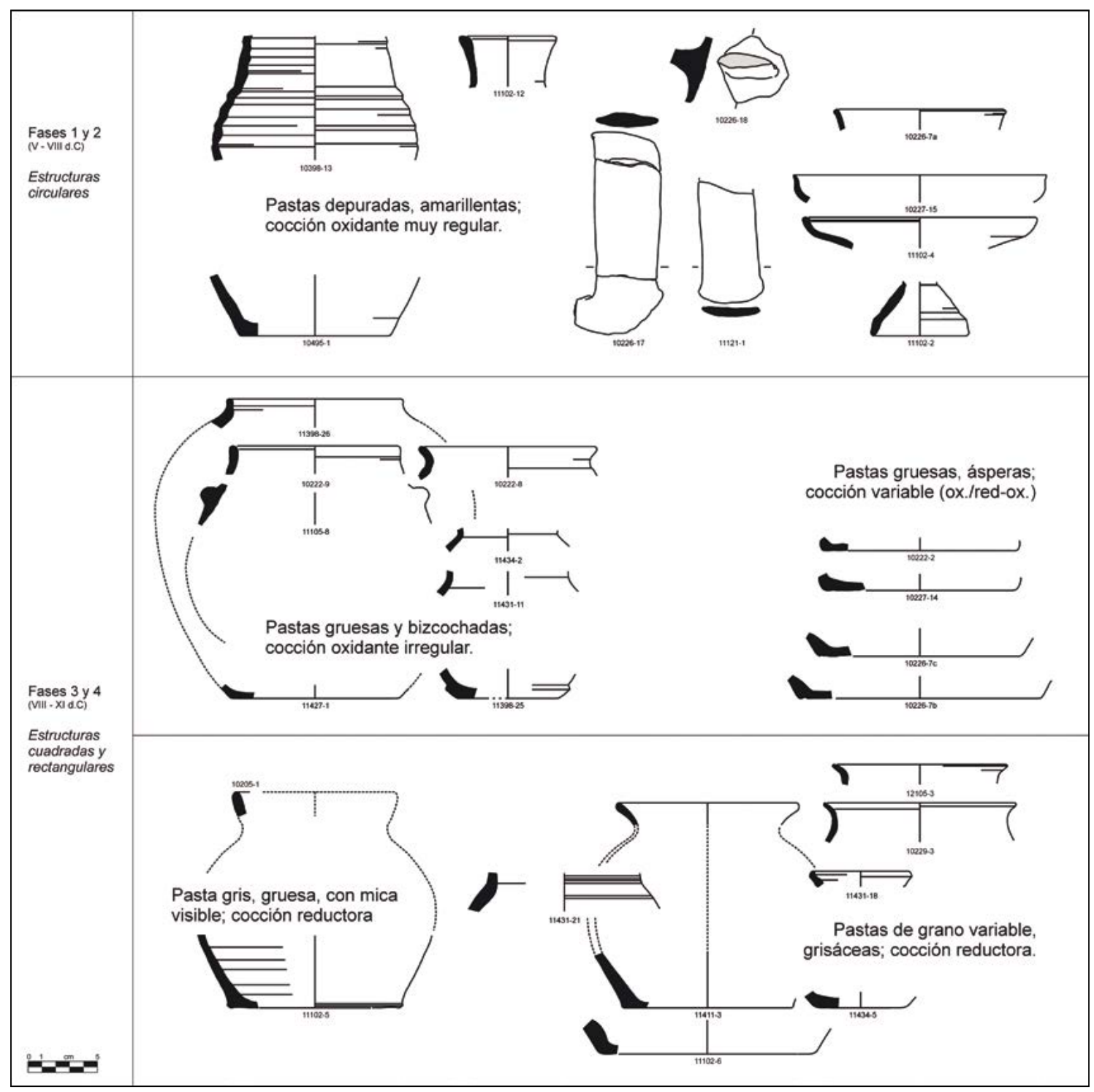

Figura 3. Clasificación de las principales formas cerámicas recuperadas en Revenga en relación con sus características macroscópicas y cronología relativa (elaboración propia).

riales en contextos in situ, con anterioridad a su caracterización macroscópica de tipo tecnológico y funcional, y la segunda es la observación de las pastas con criterio petrográfico como elemento prioritario a la hora de determinar un muestreo analítico. Nuestra primera premisa ya se ha revelado en estudios anteriores como un criterio válido -imprescindible, de hecho- para conocer en profundidad los rasgos de las cerámicas comunes, buscando la lógica interna de los conjuntos, hasta el punto de ofrecer elementos de referencia cronológica (Vigil-Escalera 2006a: 729, 2007: 377; Tejerizo 2016: 232).
Los elementos que condicionan nuestra segunda premisa metodológica no parecen estar, por el contrario, tan extendidos ya que pese a la eficacia de considerar el carácter tecnológico en las clasificaciones (Vigil-Escalera 2007: 373), los criterios que se priorizan entre las múltiples variables que condicionan la aproximación tecnológica parecen imbuidos por la necesidad de distinguir entre las producciones romanas estandarizadas y las cerámicas comunes. Así, el criterio tecnológico fundamental para buena parte de las clasificaciones consiste en identificar la factura o técnica de modelado haciendo especial hincapié en la 
velocidad de rotación aplicada al torno. En cualquier caso, es necesario tener en cuenta las limitaciones de este tipo de aproximaciones, puesto que las macrotrazas resultantes del modelado a torno enmascaran en ocasiones la utilización del urdido (Roux 1994: 49-51). La interpretación de las marcas de torno como elemento para la identificación del tipo de modelado, puede resultar engañosa también cuando se emplea la torneta mediante un giro rápido, hecho que dificulta notablemente la distinción respecto del torno de pie, que deviene prácticamente imposible (Roux y Miroschedji 2009: 166).

Pese a los problemas que puede comportar el criterio tecnológico de identificación del torneado, tras una primera divisoria general en función de la factura de las piezas, ya sea mediante un torneado lento o rápido (Vigil-Escalera 1999, 2006a; Tejerizo 2017), se identifican a continuación los principales rasgos macroscópicos de las pastas, es decir, su carácter más o menos depurado, la presencia de mayor o menor componente micáceo, calcáreo o arenoso, los acabados bruñidos o alisados, su dureza o la atmósfera de cocción (Vigil-Escalera 1999).

La naturaleza del material cerámico recuperado en Revenga, extremadamente fragmentado, escaso, muy rodado y en su mayoría informe, nos obliga a extremar la reflexión acerca de los criterios de sistematización de la cerámica y considerar todas las variables tecnológicas en juego de cara a conseguir un muestreo efectivo para la clasificación arqueométrica. La cerámica de Revenga de acabados rugosos o someramente alisados, pero con grosores bastante regulares, aunque variables entre los distintos fragmentos presenta una diversidad de pastas considerable. En algunos casos, se aprecia el urdido de algunas piezas (Roux y Jeffra 2015: 168-170), pero en ningún caso la técnica de modelado puede utilizarse como criterio predominante. Por ello, como decíamos al principio, la observación de las pastas con criterio petrográfico como elemento prioritario a la hora de determinar un muestreo analítico ha sido el elemento principal subyacente en la sistematización que presentamos.

La totalidad de fragmentos cerámicos recuperados entre las intervenciones de 2014-2016 han sido considerados, a excepción de los materiales descontextualizados obtenidos en procesos de limpieza, o de levantamiento del manto vegetal. Durante el proceso de inventario, los principales rasgos macroscópicos de la pasta en función de la naturaleza y dimensiones de las inclusiones no plásticas, la matriz arcillosa y la porosidad (Whitbread 1989, 1995, 2001; Quinn 2013: 73 79), se han descrito para cada uno de los fragmentos con independencia de su descripción genérica, a partir de una observación macroscópica con la ayuda de una lupa de 20x. Una definición precisa de las inclusiones en relación con su abundancia, dimensiones, naturaleza, forma o sorteo; del carácter homogéneo o heterogéneo de la matriz y de las características de la porosidad en cuanto a la abundancia de los poros o vacuolas, su forma y su posible origen permiten determinar con cierta precisión los grupos mayoritarios en función de los parámetros que se consideran en el análisis microscópico, que permite identificar y definir dichas variables de manera pormenorizada.

En base a los grupos determinados se identifica la proporción en la que aparecen para cada unidad estratigráfica (Fig. 4) muestreando una proporción equivalente en donde todas las unidades estén representadas, así como todas las muestras aisladas, que también deben ser incluidas en el análisis. Con ello se ha obtenido un muestreo representativo puesto que la selección incluye toda la variabilidad del conjunto de pastas. De los 75 fragmentos de cerámica seleccionados se ha preparado una lámina delgada en sección vertical para cada uno, analizada a microscopio en base a los mismos términos (Quinn 2013: 73-79).

La imposibilidad de identificar con seguridad fragmentos distintos atribuibles a un mismo individuo a causa del precario estado de conservación de los materiales ha impedido la selección de más de un fragmento por individuo determinado, por lo que no es posible por el momento evaluar con precisión la resolución petrográfica del conjunto, que estimamos bastante elevada dada la disparidad de los grupos identificados y su correlación con el análisis macroscópico en el seno de un mismo yacimiento. Las láminas delgadas han sido nuevamente agrupadas en función de su microestructura y la naturaleza de sus inclusiones, matriz y porosidad, con independencia de la clasificación macroscópica. Los grupos petrográficos han sido interpretados en términos de proveniencia y tecnología de producción a fin de reconstruir las cadenas operativas aplicadas a cada grupo. La comparación de dichos resultados con los datos macroscópicos permite proporcionar algunas pautas interpretativas del panorama cerámico observado en el yacimiento.

\section{LA CERÁMICA DEL ALTO ARLANZA Y SU TECNOLOGÍA DE PRODUCCIÓN: RESULTADOS DE LA CARACTERIZACIÓN PETROGRÁFICA}

Los resultados del análisis macroscópico y petrográfico a partir del estudio microscópico de láminas delgadas han revelado la existencia de nueve fábricas más o menos depuradas o gruesas, distinguibles por las características específicas de las inclusiones no 


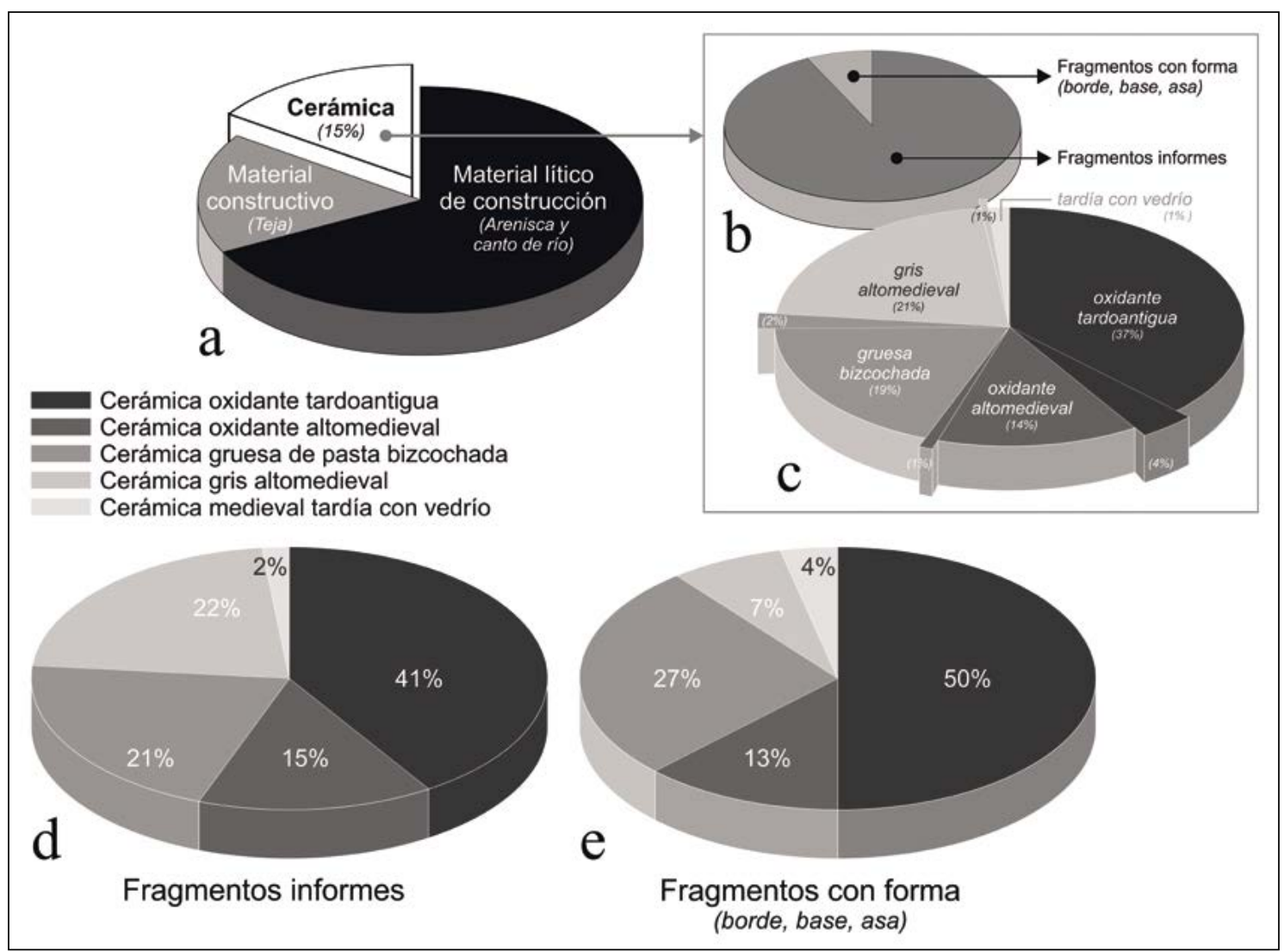

Figura 4. Gráficos sectoriales de los porcentajes de materiales cerámicos recuperados en el yacimiento de Revenga, en relación al volumen total (a), desglosados en relación a la forma (b) y tipo de cerámica al que pertenecen (c); y distribución por tipos de la cerámica informe (d) y con forma (e) (elaboración propia).

plásticas, matriz y porosidad que conforman cada una de las muestras (Fig. 5). Entre el conjunto de pastas finas, se identifica una fábrica (1) caracterizada macroscópicamente por sus pastas finas, amarillentas o ligeramente anaranjadas, de cocciones oxidantes regulares y matrices con textura variable y coloración muy homogénea, con una superficie jabonosa que se deshace al tacto. El análisis petrográfico revela su microestructura fina y arenosa, con inclusiones de formas equidimensionales y alargadas, bordes angulosos, selección variable y distribución unimodal, en un rango de dimensiones entre $0,1-0,25 \mathrm{~mm}$, por lo que consideramos una pasta fina pese al porcentaje elevado (c. $40 \%$ ) de material no-plástico. El cuarzo es predominante junto con inclusiones micáceas comunes - moscovita y biotita- que aparecen todas ellas irregularmente distribuidas en una matriz heterogénea en la que se detectan numerosas vetas y heterogeneidades texturales muy significativas que abogan por un proceso de mezcla de arcillas, o quizás de la mezcla de una pasta base con una arenisca muy triturada más o menos humedecida (Fig. 6a). La presencia de porosidad plana (5-10\%), especialmente en las zonas de cambio de textura y entre vetas, aboga también por esta interpretación.

La observación microscópica permite advertir diferencias significativas entre esta fábrica y una segunda fábrica (2) macroscópicamente muy similar a la anterior, aunque de tacto más áspero. Las inclusiones (10-20\%), equidimensionales y menos angulosas en este caso, presentan una bimodalidad clara con un sorteo de moderado a bueno en ambas fracciones (habitualmente distribuidas al $50 \%$ ). La mitad más gruesa la componen inclusiones de naturaleza variable que forman una arena entre media y gruesa $(c .0,5 \mathrm{~mm})$ con cuarzo frecuente y fragmentos de roca sedimentaria -cuarzoarenita fina o muy fina-formada por cuarzo predominante, feldespatos y algunas moscovitas; en general poco cimentados. Este panorama de inclusiones frecuentes se ve complementado por otras inclusiones claramente minoritarias, muy poco frecuentes, entre las que se cuentan algunos nódulos ar- 


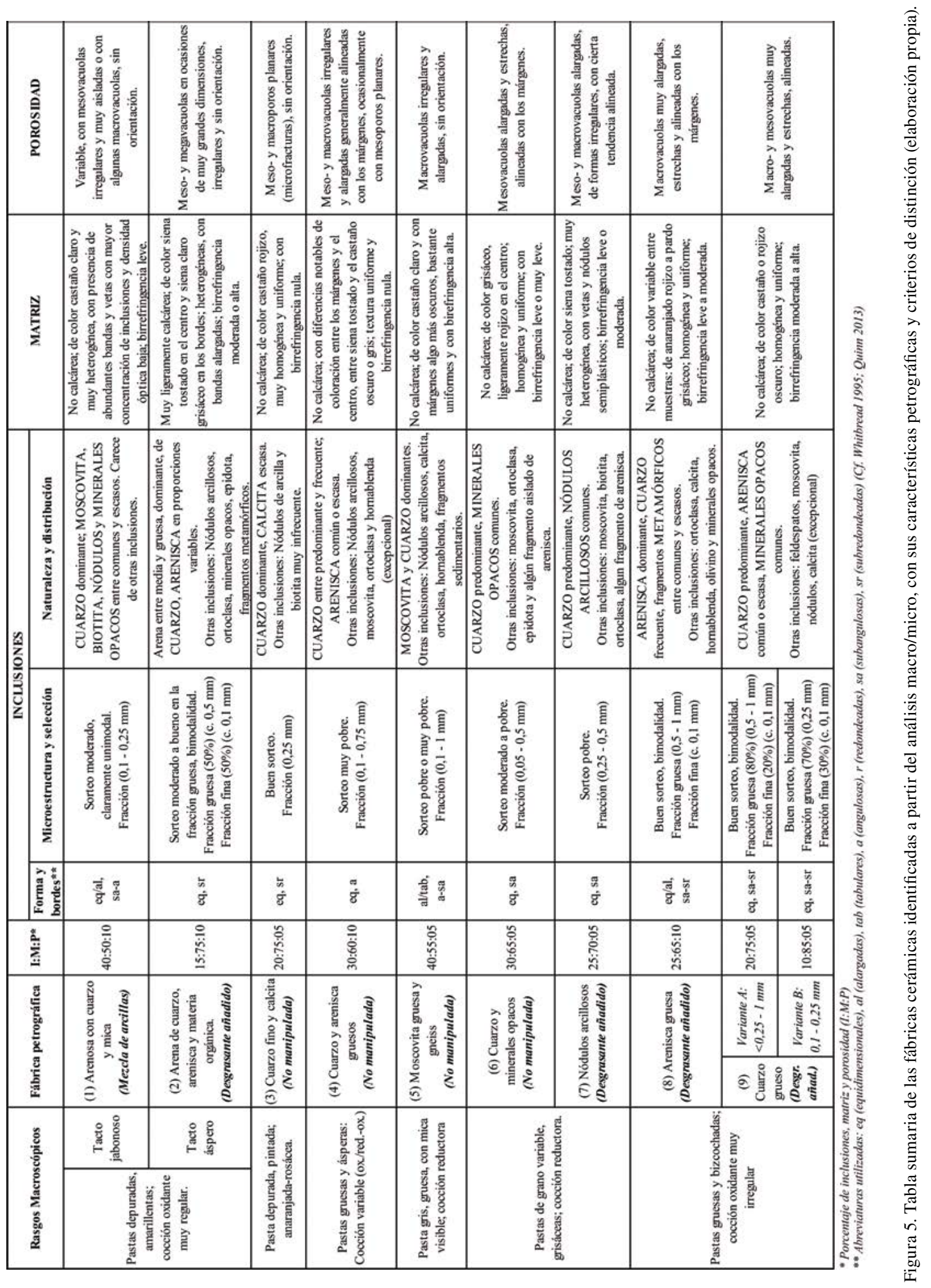




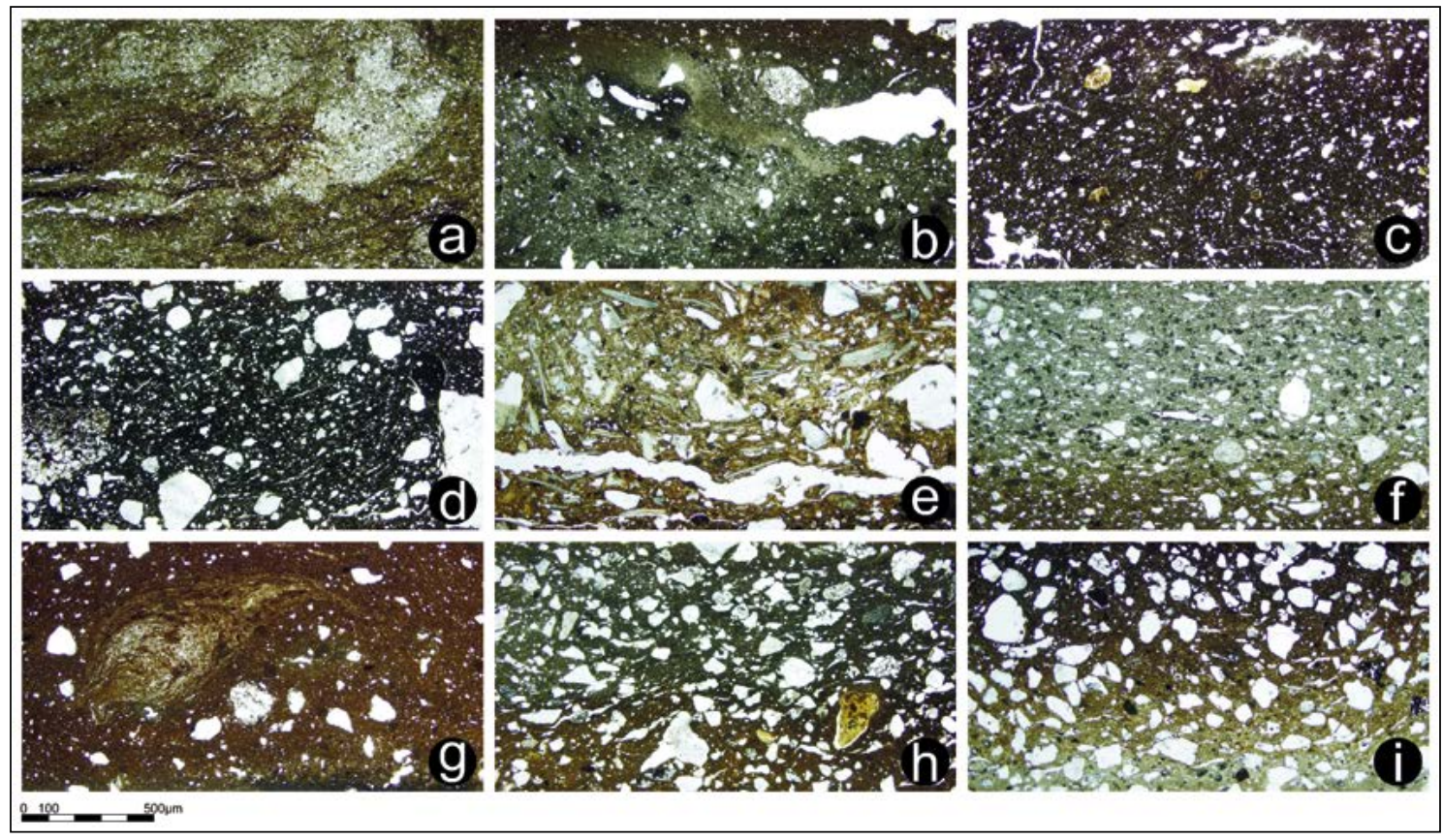

Figura 6. Microfotografías de los principales grupos cerámicos identificados. Todas ellas han sido tomadas a 20x en luz plana polarizada (fotografías E. Travé).

cillosos, ortoclasa, calcita o epidota; y una fracción fina de cuarzo monocristalino predominante $(c .0,1$ $\mathrm{mm})$ más o menos anguloso. Con matrices poco uniformes, estas pastas parecen modeladas a partir de unas arcillas quizás levemente desgrasadas con una arena de cuarzo y fragmentos de roca a los que se añade una pequeña proporción de materia orgánica, identificable a partir de los rasgos característicos de la porosidad (5-10\%). Detectamos en este sentido la presencia de poros de formas muy regulares y bordes carbonizados que responden al negativo dejado tras la cocción por un posible componente vegetal añadido (Fig. 6b).

Entre las pastas más finas, se cuenta también una fábrica (3) representada por una única muestra con decoración pintada y elaborada a base de una pasta no manipulada; con inclusiones $(20 \%)$ de origen natural, ligeramente redondeadas, mayormente de cuarzo predominante $(\leq 0,25 \mathrm{~mm})$ y con algunos nódulos de aspecto muy calcáreo, ausentes en las demás fábricas identificadas, y biotita muy infrecuente $(0,1-0,25 \mathrm{~mm})$. Presenta una matriz rojiza, no calcárea, con microfracturas (5\%) sin orientación preferente (Fig. 6c). Las seis fábricas restantes agrupan cerámicas gruesas entre las que se advierten diferencias relativas al origen de las producciones o a la tecnología de producción empleada. La principal distinción tecnológica se establece entre las pastas manipuladas o no durante la preparación en virtud de la naturaleza de sus inclusiones.

Entre las fábricas no manipuladas, una de ellas (4) incluye muestras de pastas gruesas, ásperas, de cocciones muy variables oxidantes o reductoras, pero preferentemente mixtas y en atmósferas poco controladas. Observadas a microscopio, se advierten inclusiones abundantes (25-30 \%) muy poco sorteadas, con distribución unimodal en un rango de 0,1-0,75 mm y excepcionalmente superiores que constituyen un conjunto de origen natural formado por cuarzo predominante y arenisca común o escasa. Destacan algunas inclusiones de arenisca ricas en opacos y con cimentación ferruginosa, que corresponden a una arenisca local que denominamos moteada. Todas las inclusiones presentan, aunque de manera infrecuente o muy infrecuente, nódulos arcillosos muy aislados (c. 0,25 $\mathrm{mm}$ ), y ocasionalmente calcita, plagioclasa, minerales opacos y moscovita en función de las muestras. Las matrices presentan coloraciones muy variables, habitualmente con los márgenes oscuros, pero textura uniforme. Se observan también vacuolas irregulares y alargadas, generalmente alineadas (5-10 \%) (Fig. 6d).

También con inclusiones de origen natural, otra de las fábricas (5) constituye un grupo claramente minoritario, formado por fragmentos de pastas muy gruesas, cuyo análisis macroscópico revela la presencia de inclusiones micáceas muy abundantes que confieren 
un aspecto brillante a la superficie de las piezas. El análisis microscópico permite comprobar que se trata de unas pastas moscovíticas, con abundantes (40\%) inclusiones alargadas o tabulares, procedentes de la meteorización de una roca metamórfica -quizás gneis- con cuarzo, moscovita y ocasionalmente clorita o sericita predominantes (Fig. 6e), pobremente sorteadas, pero relativamente gruesas $(0,1-1 \mathrm{~mm})$, y algunos nódulos arcillosos. El conjunto se complementa con algunas otras inclusiones muy poco frecuentes de ortoclasa, biotita u hornablenda. Las matrices son uniformes, de color castaño claro o anaranjado con los bordes algo más oscuros y la porosidad algo más escasa $(5 \%)$ que en otros grupos.

Cerrando el conjunto de fábricas gruesas sin desgrasante, la fábrica 6 agrupa un conjunto muy homogéneo de pastas exclusivamente reductoras, de tonos grisáceos, con inclusiones (15-30\%) relativamente gruesas, de origen natural entre las que abundan los elementos opacos $(0,25-0,5 \mathrm{~mm})$, probablemente ferruginosos, en proporción variable (Fig. 6f). El cuarzo (0,05-0,5 mm) es predominante o dominante, habitualmente monocristalino y muy ocasionalmente policristalino. El repertorio de inclusiones lo completan en proporciones entre escasas y muy infrecuentes la ortoclasa alterada, plagioclasa, moscovita y epidota. Las matrices arcillosas -no calcáreas en todos los casos y de tonos castaños grisáceos- tienden a rojizas en los márgenes y son bastante uniformes. Destaca la birrefringencia del conjunto, con actividad óptica variable en función de cada muestra, pero habitualmente moderada, lo que indica que las temperaturas de cocción no fueron especialmente elevadas. La porosidad es muy escasa (1-5\%) solo con algunas vacuolas menudas y aisladas, muy alargadas y estrechas y con orientación preferente alineada respecto de las paredes del vaso.

Entre las pastas grises, reductoras, pero con cocciones bastante irregulares, se incluye también la primera de las fábricas manipuladas (7). El porcentaje de inclusiones (15-25\%) es sensiblemente menor que en otras fábricas gruesas e incluye una arena media (0,25-0,5 mm) de cuarzo predominante. Los nódulos de arcilla de naturaleza muy heterogénea, semiplásticos con bordes marcados, alta densidad óptica y discordancia respecto de la matriz, de colores rojizos, en ocasiones con tendencia opaca aparecen junto con bandas y vetas rojizas en unas matrices muy heterogéneas con birrefringencia destacable y poros también escasos (3-5 \%) e irregulares (Fig. 6g). El conjunto permite interpretar que la elaboración de los vasos se realiza a partir de una pasta gruesa con las inclusiones anteriormente mencionadas, en su mayoría de cuarzo, y probablemente de origen natural, pero con una ma- nipulación o preparación específica de la pasta, desgrasada con arcilla seca triturada añadida durante el amasado y quizás con una arena adicional de cuarzo y arenisca.

Finalmente, durante el análisis macroscópico pudimos identificar una serie de fragmentos, muy abundantes, de pastas gruesas, bizcochadas, con cocciones preferentemente oxidantes, pero muy irregulares. En este grupo -aparentemente un cajón de sastre- pudimos identificar dos tipos de producciones que observadas a microscopio se revelan petrográficamente muy homogéneas y que responden a dos producciones manipuladas diferentes. En ambos casos se trata de pastas claramente desgrasadas, con matrices muy finas y grandes inclusiones bien sorteadas que responden al proceso de adición voluntaria de una arena gruesa durante el pastado.

En una de las fábricas (8) la arena gruesa añadida está formada por una amalgama heterogénea de clastos en donde abundan los fragmentos de arenisca cuarzoarenita muy finas, con poca cimentación y compactación relativa- y cuarzo por lo general monocristalino (Fig. 6h). Son habituales también los fragmentos de roca metamórfica siendo siempre los menos frecuentes del conjunto. Preferentemente incluyen fragmentos de pizarras arenosas o filitas muy finas que coocurren en algunas muestras. Las matrices, no calcáreas, presentan todas ellas una textura uniforme, y una actividad óptica variable, entre nula, muy leve o moderada, con tonos variables que oscilan entre el anaranjado o rojizo y los tonos pardos o grisáceos, habitualmente con una ligera heterogeneidad debida a la diferencia de tono entre los márgenes y el centro de la sección. La fábrica es bastante porosa (10-15\%), con vacuolas muy alargadas (c. 0,5-1 mm) y estrechas con orientación preferente alineada.

En la otra fábrica (9), la predominancia del cuarzo, algo anguloso y bien sorteado, es evidente (Fig. 6i). Se trata, por tanto, de una adición de arena gruesa de cuarzo $(0,5-1 \mathrm{~mm})$ mono- y policristalino, con extinciones recta y ondulante respectivamente en la mayoría de muestras, que incluye ocasionalmente algunos fragmentos de roca sedimentaria escasos, de cuarzoarenitas muy finas. También son muy escasas, pero presentes en la mayoría de muestras, las inclusiones opacas y de ortoclasa. El carácter añadido de esta arena contrasta con las inclusiones de origen natural presentes en la arcilla, que forman una fracción fina de cuarzo monocristalino predominante (c. 0,1 mm). En el conjunto de esta fábrica podemos distinguir una variante $(A)$, algo más gruesa $(<0,25-1 \mathrm{~mm})$, con cuarzo predominante y otra variante $(\mathrm{B})$ algo más fina, con menor cantidad de fracción fina $(0,1-0,25 \mathrm{~mm})$ y cuarzo predominante o dominante, mejor sorteado. Ambas 
variantes presentan texturas uniformes en la matriz, con coloraciones heterogéneas que oscilan entre el castaño más o menos oscuro y el rojizo, y todas ellas con actividad óptica entre moderada y alta, que denota unas temperaturas de cocción relativamente bajas. La porosidad es escasa (c. $5 \%$ ) en ambas variantes, con vacuolas alargadas y alineadas de dimensiones variables.

\section{DISCUSIÓN: PROVENIENCIA, TECNOLOGÍA DE PRODUCCIÓN EN REVENGA Y ALGUNOS PROBLEMAS INTERPRETATIVOS}

El estudio de los materiales cerámicos de Revenga ha revelado la existencia de una elevada variabilidad interna de unas producciones cerámicas entre las que se cuentan unos volúmenes mayoritarios de fabricación local, junto con algunos individuos importados. La determinación del origen de estas cerámicas en términos de proveniencia está aún en proceso, por lo que debemos ser necesariamente parcos en su interpretación. Un análisis futuro de los materiales líticos y de muestras geológicas obtenidas del mismo yacimiento deberá contribuir a esclarecer este aspecto. Por ahora, el conjunto mayoritariamente refleja la existencia de una serie de producciones locales, que trabajan a partir de unas materias primas muy similares y que presentan diferencias entre ellas fundamentalmente de carácter tecnológico, aunque se pueden identificar dos producciones que -en términos de provenienciase alejan de las fábricas habituales, siendo una de estas producciones una importación clara.

Nos referimos a la fábrica 5, relacionada tal vez con un gneis metamórfico y rica en inclusiones moscovíticas, para la que sugerimos un origen no local. El origen preciso de esta producción nos resulta ignoto por el momento, aunque formaciones geológicas de este tipo son habituales en la Sierra de Guadarrama y los alrededores de Madrid, en donde nos consta la presencia de este tipo de cerámica altamente micácea (Vigil-Escalera 2006a: 731). Tampoco parece local, aunque pudiera proceder de algún territorio cercano, la fábrica 3 , que incluye una única muestra en la que el componente calcáreo de las inclusiones es muy remarcable, hecho que no es habitual entre los productos que consideramos locales por lo que, con las debidas precauciones, la interpretamos como importada. El resto de fábricas, con inclusiones habituales de cuarzo y arenisca añadidas o no, pueden interpretarse como producciones locales a juzgar por la cartografía geológica disponible y los muestreos geológicos in situ. La particular presencia de inclusiones opacas o ferruginosas de la fábrica 6 tampoco excluye el origen local de la misma, dado que dichas inclusiones ferruginosas son habituales en las formaciones rocosas presentes en el entorno de Revenga.

Entre las producciones locales, las diferencias tecnológicas en los procesos de preparación de la pasta mediante técnicas concretas como la adición de desgrasantes, la mezcla de arcillas, la selección de materia prima -una arcilla gruesa en origen que no requiera de aditivos- o la homogeneidad y consistencia del pastado son interpretables en términos cronológicos. La comparación del análisis de los materiales con los contextos estratigráficos en los que han sido recuperados nos permite proponer una cronología relativa para distintas preparaciones de las pastas en términos de anterioridad y posterioridad (Fig. 7).

Las implicaciones de esta sistematización son significativas por distintas razones. La primera de ellas es que existe una buena correlación entre el análisis macro y micro. Es posible determinar grupos de pastas bien definidos desde el punto de vista petrográfico y, a la vez, identificar algunos rasgos macroscópicos definitorios también de dichos grupos. Es importante, asimismo, llamar la atención sobre aquellas producciones que macroscópicamente deberíamos incluir en un mismo conjunto -las fábricas 1 y 2 por ejemplopero que, al ser analizadas a microscopio, revelan la utilización de tecnologías de producción específicas. Además, debemos remarcar también la existencia de algunas particularidades tecnológicas que, al quedar adscritas a una fase concreta del registro arqueológico nos permiten interpretar la existencia de transformaciones de carácter técnico, quizás debidas a transformaciones en los circuitos de distribución o a la presencia de influencias externas en la zona.

Un primer dato interesante a tener en cuenta es que la práctica de la mezcla de arcillas, es decir, de la disolución durante el pastado de dos arcillas complementarias mezcladas en su estado plástico, que advertimos en la fábrica 1, tiene en el asentamiento una duración limitada. Este fenómeno, que no es ajeno en el territorio castellano (Sempere 1982: 28) y que aún hoy conocemos gracias a estudios de carácter etnográfico (Sempere 1982: 20), parece limitado en Revenga a un periodo muy concreto, anterior a la transformación del poblado y relacionado con las fases más tempranas de ocupación. La adición ocasional o no de materia vegetal o desgrasante orgánico propio de la fábrica 2 , aunque pudo coexistir con la anterior, parece responder a un momento de ocupación más tardío, aunque los rasgos macroscópicos de ambas sean muy similares. La fábrica 3 también se asocia estratigráficamente al periodo temprano del asentamiento, en relación con las estructuras circulares. Su carácter foráneo y la escasa representatividad que le confiere 


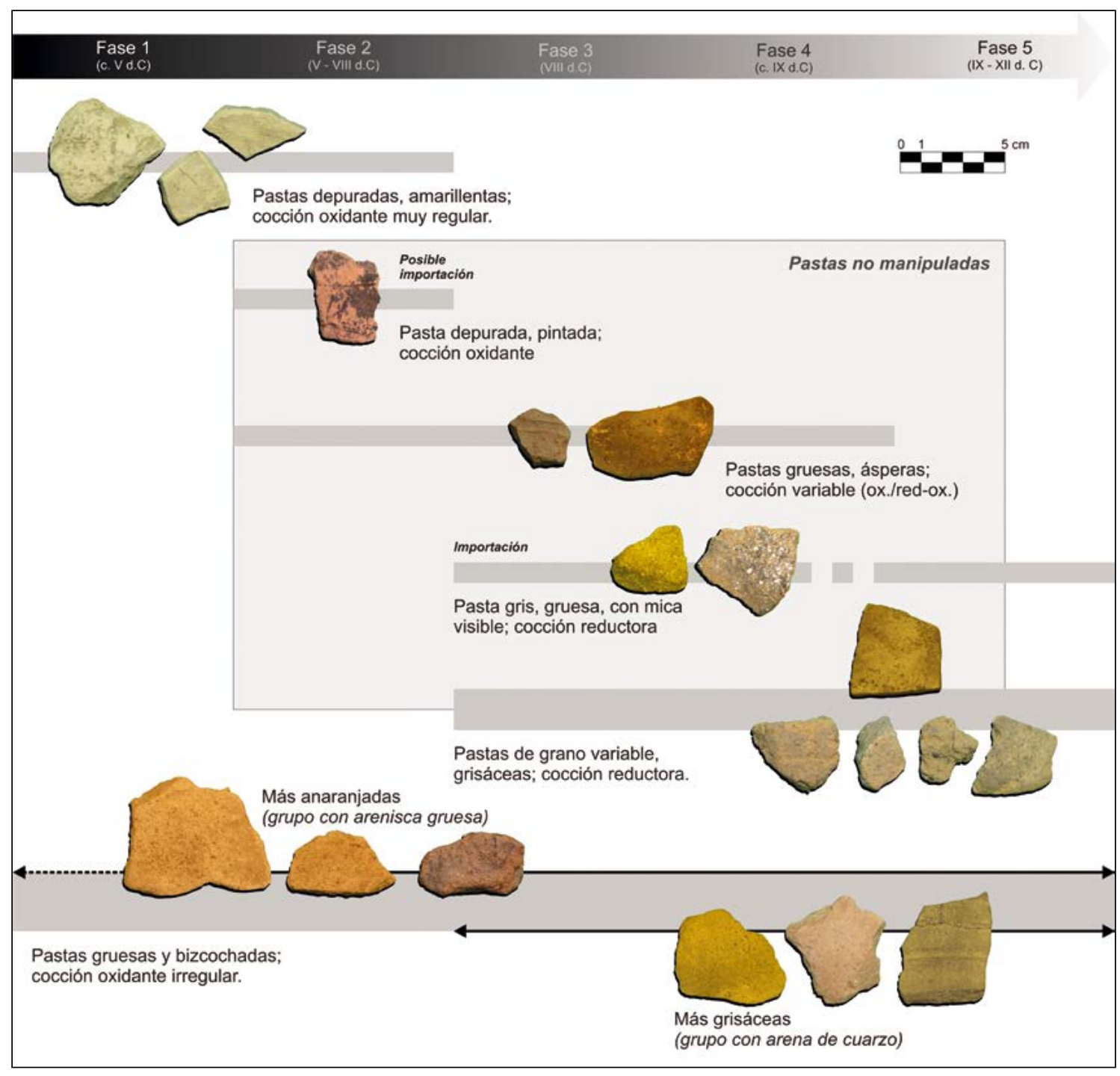

Figura 7. Cuadro de clasificación de los principales grupos cerámicos identificados en relación con el contexto estratigráfico, su cronología relativa y los procesos tecnológicos que operan en las distintas fábricas (elaboración propia).

la única muestra relacionada que la identifica nos lleva a pensar que dicha importación debió de constituir un fenómeno aislado.

A partir de la transformación del asentamiento, probablemente a partir de la construcción de la iglesia y el cementerio, el panorama cerámico experimenta algunos cambios. Desde este momento, que a grandes rasgos situaríamos hacia el siglo VIII, en adelante encontramos pastas más gruesas, con inclusiones claramente perceptibles a simple vista. Las cocciones reductoras adquieren preeminencia, aunque todavía se mantienen las oxidantes, si bien más irregulares. El análisis microscópico de estas pastas nos permite dis- tinguir entre unos productos claramente manipulados a partir de la adición de desgrasantes específicos -probablemente con la voluntad de mejorar las características tecnológicas de la producción (Kilikouglou et alii 1995)- y otros con inclusiones de origen natural, que responden a una selección de arcillas gruesas en origen que posibilitan la producción de unos recipientes de uso preferentemente culinario en un momento en que la cerámica de mesa ha sido tal vez sustituida por los enseres de madera (Blas 1995).

Si examinamos la presencia de estas pastas gruesas desgrasadas en los contextos estratigráficos, advertimos que las pastas desgrasadas con cuarzo son exclu- 
sivas de las fases más tardías del asentamiento, mientras que cerámica rica en arenisca y fragmentos de roca no resulta exclusiva de ningún periodo, apareciendo repetidamente y de forma abundante en toda la secuencia estratigráfica pese a ser más abundante en las fases tempranas. Esta presencia mayoritaria de las pastas desgrasadas con fragmentos de roca triturada, su abundancia y su continuidad a lo largo del asentamiento nos lleva a pensar en este tipo de cerámicas como un elemento de tradición muy arraigada, altamente funcional y utilitario, que prácticamente no experimenta cambios durante un periodo de tiempo muy prolongado. Aun así, nuevamente alrededor del siglo VIII y al compás de la transformación del poblado parece producirse una innovación técnica que viene marcada por la utilización del cuarzo en detrimento de los fragmentos de roca. Las producciones con arenisca no desaparecen, pero se verán forzadas a convivir con una cerámica probablemente de mejor calidad en términos de funcionalidad culinaria.

Es significativo el hecho de que la fábrica 5, que constituye una importación clara, es específica de este momento y que no se documenta en ningún caso en relación con las fases antiguas, por lo que es posible que la llegada de un contingente poblacional foráneo, por escaso que este fuera, hubiera contribuido a la transformación del asentamiento, posiblemente a su cristianización (Álvaro et alii 2018d: 146), y quizás también a la introducción de nuevas formas de producción cerámica en la zona del Alto Arlanza fruto de la transferencia cultural. Las pastas gruesas no desgrasadas, en cambio, parecen tener una duración mayor y no presentan una correlación tan directa con las fases de ocupación. Así, la fábrica 4 se detecta ya en la segunda fase de estructuras circulares, pero es predominante en la estratigrafía de las estructuras de planta cuadrada.

Estas fábricas incluyen en su mayoría cerámica a mano, ocasionalmente terminada con la ayuda de un torno o torneta, que con mayor o menor esmero uniformiza unas paredes preferentemente urdidas, hecho que es habitual en los materiales de este periodo y para el cual contamos con paralelos (Pérez y González 2009: 327). Hay que tener en cuenta que la distinción entre cerámica modelada y cerámica torneada (Bermejo 2011: 343) parece válida para distinguir entre las producciones algo más suntuarias de tradición romana y las producciones comunes de carácter regional, pero, fruto de esa voluntad de identificar las producciones tardorromanas, se puede correr el riesgo de uniformizar en exceso las comunes y de simplificar los condicionantes tecnológicos que definen especialmente la cerámica culinaria limitando la tecnología al método de modelado y conside- rando la naturaleza depurada o no depurada de la pasta como un elemento meramente físico (VigilEscalera 2007: 373) al margen de las posibles recetas de preparación y de las variables tecnológicas, es decir antrópicas, en los procesos de selección, procesado y adición de desgrasantes o explotación de arcillas gruesas en su depósito original.

La identificación del torneado, especialmente desde la óptica macroscópica, tampoco está exenta de problemas. La supuesta sencillez de la identificación de facturas a torneado rápido o lento que atribuyen las características líneas horizontales regulares y perfectamente marcadas a una velocidad rápida de rotación (Centeno et alii 2016: 265) excluye la posibilidad de que una pieza urdida sea terminada sobre el torno con una cierta diligencia, mediante un giro rápido, técnica que es bastante frecuente aún hoy día para los recipientes de gran formato, como los tradicionales cossis de Quart (Girona) entre otras muchas piezas de dimensiones considerables en cuya superficie no se advierten irregularidades (Vicens y Travé 2018). La identificación fiable del urdido en la mayoría de casos es posible a partir de la detección de rollos relictos en una sección vertical del vaso observada en lámina delgada (Quinn 2013: 176-179). Del mismo modo, atribuyendo de manera sistemática las irregularidades en el grosor de las paredes al torneado lento como acabado para embellecer unas paredes levantadas a mano excluye la posibilidad de que un alfarero accidental con poca pericia esté levantando a torno una cerámica con más o menos irregularidades para su uso personal, sin especial cuidado por los acabados y al margen de las producciones profesionales dedicadas al comercio, por regional o local que este pueda ser en un momento determinado.

El panorama cerámico en Revenga, se revela por tanto variopinto desde esta óptica específica. Poco más podemos aventurar por ahora acerca de las producciones del Alto Arlanza. En Revenga no se ha detectado ningún elemento relacionado con la producción de cerámica, pero las características geológicas de los materiales utilizados sugieren la explotación de materias primas locales en la mayoría de casos. Por ahora, debemos suponer la existencia de pequeños centros de producción con circuitos de distribución y radios de acción limitados, que probablemente explotan fuentes de materia prima comunes, pero desarrollan en cada caso cadenas operativas genuinas. La presencia de esta variabilidad cerámica en un único asentamiento como el de Revenga, sugiere una cierta complejidad en el grado de interacción territorial en un espacio regional delimitado, permeable a las influencias exteriores, pero con un marcado carácter autosuficiente. 


\section{CONCLUSIONES Y RETOS DE FUTURO: HACIA UN ANÁLISIS INTEGRAL DE LOS MATERIALES CERÁMICOS}

El estudio ceramológico de los materiales de Revenga nos permite remarcar el potencial de las aproximaciones de este tipo y de las posibilidades de una cerámica que muy a menudo se ha visto relegada como un mero interludio entre el panorama cerámico de época romana y las producciones medievales de época feudal (Aranda 2014: 109-110). No podemos perder de vista las dificultades que entraña la arqueología de las aldeas, propiamente dicha, con grandes extensiones de terreno y unos restos arqueológicos muy parcos y complejos de interpretar. En esta coyuntura, la ausencia de secuencias estratigráficas completas dificulta notablemente el estudio y acaba por proponer horquillas cronológicas muy amplias e indefinidas que a menudo son el resultado de prácticas que deben evitarse. La primera de ellas es la priorización de las producciones finas atribuibles a la influencia romana en el territorio, especialmente en los momentos en que estas conviven o no con producciones utilitarias de carácter local. La ausencia de este tipo de materiales en el yacimiento de Revenga, nos obliga necesariamente, y tal vez afortunadamente, a detenernos en la cerámica común.

Por otro lado, el estudio de la cerámica no debe ser entendido como una mera herramienta auxiliar, de tipo cronológico -que data o no data un yacimiento concreto- al margen de las transformaciones culturales, de los cambios de uso y de la evolución de maneras de hacer que son el reflejo de un ciclo productivo de carácter específico. En este sentido, es importante que seamos capaces de desvincular las similitudes entre la cerámica protohistórica con las altomedievales, que en ningún caso se trata de recuperación de producciones antiguas sino de necesidades vitales que presentan algunas semejanzas entre un periodo y otro y que, por lo tanto, adoptan soluciones tecnológicas parecidas (Azkarate et alii 2003: 323). En cualquier caso, estas opciones tecnológicas no suponen una creación nueva ni tampoco una resurrección más o menos artificiosa de prácticas antiguas, sino la pervivencia de unas formas de tecnología tradicional, bien adaptada a las necesidades a las que tiene que dar respuesta, que se mantienen vigentes durante siglos a pesar de que la uniformización cultural de las sociedades romanas urbanizadas acabe ocultando en parte la presencia de elementos culturales subyacentes en ámbitos más apartados de los circuitos principales (Macías y Cau 2012: 528).

Para el caso del Alto Arlanza, ya se ha hecho notar en trabajos anteriores que el origen del poblamiento se remonta al periodo altomedieval (Padilla y Álvaro 2010: 286), si bien los estudios recientes abogan por una ocupación más temprana de lo tradicionalmente asumido. Nada parece indicar, por ahora que el poblamiento en el asentamiento de Revenga sea anterior a los siglos IV-V, sin que conozcamos por ahora el origen de estas comunidades. En cualquier caso, el panorama cerámico estudiado en relación con una secuencia estratigráfica clara y examinado en términos tecnológicos nos ha permitido detectar la presencia o ausencia, en las distintas fases que surgen de la interpretación del registro arqueológico, de unas técnicas de producción determinadas que, en ocasiones conviven y en otros casos nos muestran la sustitución de antiguas prácticas por otras de carácter más novedoso. En Revenga, este carácter evolutivo de las producciones, analizado en función de los análisis macro y microscópicos de la producción en relación con la secuencia estratigráfica, nos permite advertir a grandes rasgos un periodo entre los siglos V y VIII en el cual se detectan unas cerámicas producidas a partir de pastas no manipuladas, cuya arcilla está muy poco procesada con anterioridad al modelado. Este tipo de producciones conviven con algunas recetas en las que la pasta es sistemáticamente procesada en base a unos parámetros definidos que experimentan variaciones a lo largo del tiempo. La naturaleza de las inclusiones y los rasgos tecnológicos de esta cerámica nos permiten inferir a priori un origen local de la producción que, si bien queda limitado a un circuito regional reducido, no está exento de una cierta complejidad interna. Un número variable de productores están operando en la zona, no sabemos si en varios talleres estables o desplazándose por la región en lo que a todas luces parece un esquema de producción profesionalizado.

Este carácter profesional que advertimos en las producciones se debe fundamentalmente a las variaciones en la receta probablemente debidas a la necesidad de adaptar el producto a unas necesidades específicas de optimización de la vajilla de tipo culinario, mientras que las piezas de mesa y de servicio probablemente hayan sido sustituidas por otro tipo de útiles. Los desencadenantes de la variación tecnológica nos resultan por ahora desconocidos, pero podemos aventurar como hipótesis la incorporación de algún contingente poblacional externo que además de algunas producciones foráneas habría llegado también con prácticas tecnológicas diferenciadas. La complejidad del estudio cerámico hace necesaria, especialmente en el contexto actual de las investigaciones, una apuesta deliberada por los trabajos de caracterización analítica de estas producciones, con el objetivo fundamental de discernir entre las diferentes producciones que integran la cerámica común, así como de profundizar 
en las transformaciones técnicas que operan en el contexto de la configuración de la sociedad medieval; aproximaciones a las que hemos querido contribuir con este trabajo.

\section{AGRADECIMIENTOS}

Este trabajo se en incluye entre las tareas habituales del Grupo de Investigación en Arqueología Medieval y Postmedieval de la Universitat de Barcelona (GRAMP.UB), reconocido y consolidado por la Generalitat de Catalunya (2017-SGR-833-GRC). La investigación presentada forma parte de los resultados del proyecto titulado "La formación del paisaje medieval: el origen de la red aldeana en el Alto Arlanza", financiado por la Diputación de Burgos, Junta de Castilla y León y Comunero de Revenga (Ayuntamientos de Quintanar, Canicosa y Regumiel de la Sierra).

\section{BIBLIOGRAFÍA}

Álvaro, K., Travé, E. y López, M. D. 2018a: “Excavaciones arqueológicas en el yacimiento altomedieval de Revenga: Nuevos datos para el conocimiento de los espacios de hábitat altomedieval en el Alto Arlanza (Burgos)", Territorio, Sociedad y Poder 13, 5-21. https://doi.org/10.17811/ tsp.13.2018.5-21

Álvaro, K., Travé, E. y López, M. D. 2018b: "El yacimiento arqueológico de Revenga (Comunero de Revenga, Burgos) y su estructura de poblamiento: secuencia cronológica y ordenación del espacio de hábitat (s. V-IX)", Archeologia Medievale 45, 379393.

Álvaro, K., Travé, E. y López, M. D. 2018c: “Construcciones altomedievales en materiales perecederos en el yacimiento de Revenga (Burgos): algunas reflexiones para su interpretación arqueológica", Arqueología de la Arquitectura 15, https://doi. org/10.3989/arq.arqt.2018.005

Álvaro, K., Travé, E. y López, M. D. 2018d: "La acción monástica y eremítica en los procesos de poblamiento altomedievales (s. VI-IX): Los conjuntos singulares del Alto Arlanza y sus problemas interpretativos", Arqueología y Territorio Medieval 25, 145-167. https://doi.org/10.17561/aytm. v25.5

Aranda, R. 2014: “Cerámica de época visigoda: una historia de la investigación”, Anales de Prehistoria y Arqueología 30, 107-131.

Azkarate, A., Núñez, J. y Solaun, J. L. 2003: "Materiales y contextos cerámicos de los siglos VI al X en el País Vasco", L. Caballero, P. Mateos y M. Retuerce (eds.), Cerámicas tardorromanas y altomedievales en la península ibérica. Ruptura y continuidad, II Simposio de Arqueología, Anejos del Archivo Español de Arqueología XXVIII, Madrid, 321-370.

Azkarate, A. y Solaun, J. L. 2016: "La cerámica altomedieval en el País Vasco (siglos V - X): producciones, modelos productivos y patrones de consumo", A. Vigil-Escalera y J. A. Quirós (eds.), $L a$ cerámica de la Alta Edad Media en el cuadrante noroeste de la península ibérica (siglos V-X). Sistemas de producción, mecanismos de distribución y patrones de consumo, Bilbao, 193-228.

Bermejo, J. 2011: "La cerámica común de mesa, cocina y despensa en el Alto Duero durante el periodo bajoimperial: Un ensayo de clasificación", Espacio, Tiempo y Forma. Serie I, Nueva época. Prehistoria y Arqueología 4, 337-358. https://doi. org/10.5944/etfi.4.2011.10759

Blas Cortina, M. Á, de 1995: "Vasos de madera y vasos cerámicos. Un probable origen romano de ciertas formas en las vajillas de madera de la tornería tradicional", Boletín del Seminario de Estudios de Arte y Arqueología 61, 174-183.

Burillo, F., Cano, M. A. y Sáez, M. E. 2009: "La cerámica celtibérica”, D. Bernal y A. Ribera (eds.), Cerámicas hispanorromanas. Un estado de la cuestión, Cádiz, 191-187.

Caballero, L., Mateos, P. y Retuerce M. (eds.) 2003: Cerámicas tardorromanas y altomedievales en la península ibérica. Ruptura y continuidad, II Simposio de Arqueología, Anejos del Archivo Español de Arqueología XXVIII, Madrid.

Centeno, I. M., Palomino, A. L. y Negredo, M. 2016: "Transición y continuidad Época Romana - Alta Edad Media en el sur de Palencia: los contextos cerámicos de la $2^{\mathrm{a}}$ mitad del s. V de Soto de Cerrato", A. Vigil-Escalera y J. A. Quirós (eds.), $L a$ cerámica de la Alta Edad Media en el cuadrante noroeste de la península ibérica (siglos V-X). Sistemas de producción, mecanismos de distribución y patrones de consumo, Bilbao, 255-278.

Gutiérrez, J. A. y Bohigas, R. (eds.) 1989: La cerámica medieval en el norte y noroeste de la Península Ibérica. Aproximación a su estudio, León.

Gutiérrez, J. A. y Miguel, F. 2009: "La cerámica altomedieval en León: producciones locales y andalusíes de Puerta Obispo", J. Zozaya, M. Retuerce, M. Á. Hervás y A. De Juan (eds.), Actas del VIII Congreso Internacional de Cerámica Medieval, Tomo I, Ciudad Real, 443-462.

Hernández, J. A. y Bienes, J. J. 2003: “Cerámicas hispano-visigodas y de tradición en el valle medio 
del Ebro", L. Caballero, P. Mateos y M. Retuerce (eds.), Cerámicas tardorromanas y altomedievales en la península ibérica. Ruptura y continuidad, II Simposio de Arqueología, Anejos del Archivo Español de Arqueología XXVIII, Madrid, 307-319.

Kilikoglou, V., Vekinis, G. y Maniatis, Y. 1995: "Toughening of ceramic earthenwares by quartz inclusions: an ancient art revisited", Acta Metallurgica et Materialia 43 (8), 2959-2965. https:// doi.org/10.1016/0956-7151(95)00006-h

Larrén, H., Blanco, J. F., Villanueva, O., Caballero, J., Domínguez, A., Nuño, J., Sanz, F. J., Marcos G. J., Martín, M. Á. y Misiego, J. 2003: "Ensayo de sistematización de la cerámica tardoantigua en la cuenca del Duero", L. Caballero, P. Mateos y M. Retuerce (eds.), Cerámicas tardorromanas y altomedievales en la península ibérica. Ruptura y continuidad, II Simposio de Arqueología, Anejos del Archivo Español de Arqueología XXVIII, Madrid, 273-306.

López, M. D., Álvaro, K. y Travé, E. 2016a: Yacimiento Arqueológico de Revenga. Iglesia, necrópolis, aldea, Burgos.

López, M. D., Álvaro, K. y Travé, E. 2016b: "Rock-cut cemeteries and settlement processes at the Upper Arlanza Basin (Burgos, Spain): A late antique and early medieval landscape analysis", Zephyrus 78, 173-191. https://doi.org/10.14201/zephyrus 201678173191

Macías, J. M. y Cau M. Á. 2012: "Las cerámicas comunes del nordeste peninsular y las Baleares (siglos V-VIII): balance y perspectivas de la investigación”, D. Bernal y A. Ribera (eds.), Cerámicas hispanorromanas II. Producciones regionales, Cádiz, 511-542.

Padilla, J. I. y Álvaro, K. 2010: "Necrópolis rupestres y el poblamiento altomedieval en el Alto Arlanza (Burgos)", En la España Medieval 33, 147-170.

Padilla, J. I. y Álvaro, K. 2013: "Los asentamientos altomedievales del Alto Arlanza (Burgos). El despoblado medieval de Revenga", Pyrenae 44/1, 1141.

Pérez, F. y González, M. L. 2009: "El material cerámico de la antigüedad Tardía de «El Pelambre»", M. L. González (ed.), "El Pelambre”, Villaornate, León: el horizonte Cogotas I de la edad del bronce y el periodo tardoantiguo en el Valle medio del Esla, Grupo TRAGSA, 321-340.

Quinn, P. S. 2013: Ceramic Petrography: The Interpretation of Archaeological Pottery and Related Artefacts in Thin Section, Oxford.

Quirós, J. A. 2014: “Aristocracias, poderes y desigualdad social en la primera Edad Media en el País
Vasco”, R. Catalán, P. Fuertes y J. C. Sastre (eds.), Las fortificaciones en la tardoantigüedad: élites y articulación del territorio (Siglos V-VIII d. C.), Madrid, 143-158.

Quirós, J. A. 2017: "Identidades locales y despoblamiento en la Baja Edad Media", Reti Medievali Rivista 18/2, http://doi.org/10.6092/15932214/5327.

Roig, J. 2009: "Asentamientos rurales y poblados tardoantiguos y altomedievales en Cataluña (siglos VI al X)", J. A. Quirós (ed.), The archaeology of early medieval villages in Europe, Bilbao, 207251.

Roux, V. 1994: "La technique du tournage: définition et reconnaissance par les macrotraces", D. Binder y J. Courtin, J. (dir.), Terre cuite et société: la céramique, document, technique, économique, culturel, Actes des 14es Rencontres internationales d'archéologie et d'histoire d'Antibes, Juan-lesPins, 45-58.

Roux, V. y Jeffra, C. 2015: "The spreading of the potter's wheel in the Ancient Mediterranean. A social context-dependent phenomenon", W. Gauss, W. Klebinder-Gauss y C. von Rüden (eds.), The Transmission of Technical Knowledge in the Production of Ancient Mediterranean Pottery, Proceedings of the International Conference at the Austrian Archaeological Institute, Österreichisches Archäologisches Institut, 165-182.

Roux, V. y Miroschedji, P. de 2009: "Revisiting the History of the Potter's Wheel in the Southern Levant", Levant 41 (2), 155-173. https://doi.org/10.11 79/007589109x12484491671095

Sempere, E. 1982: Rutas a los Alfares. España-Portugal, Barcelona, 1982.

Tejerizo, C. 2016: “Construyendo la casa por los cimientos: consideraciones acerca de la cerámica de la primera Alta Edad Media en la parte central de la cuenca del Duero", A. Vigil-Escalera y J. A. Quirós (eds.), La cerámica de la Alta Edad Media en el cuadrante noroeste de la península ibérica (siglos $V$-X). Sistemas de producción, mecanismos de distribución y patrones de consumo, Bilbao, 229-254.

Tejerizo, C. 2017: "Presencia de terra sigillata hispánica tardía meridional en contextos al norte del sistema central. La Cabeza de Navasangil", Ex Officina Hispana. Boletín de la Sociedad de Estudios de la Cerámica Antigua en Hispania (SECAH) 8, 93-97.

Vicens, J. y Travé, E. 2018: "La terrissa popular de Josep Escortell i Cerqueda: La tipologia de Quart", Estudis del Baix Empordà 37, 97-129.

Vigil-Escalera, A. 1999: "Evolución de los morfotipos de cerámica común de un asentamiento rural visi- 
godo de la meseta (Gózquez de arriba, San Martín de la Vega, Madrid)". Arqueohispania 0.

Vigil-Escalera, A. 2004: "Cerámicas tardorromanas y altomedievales en Madrid", L. Caballero, P. Mateos y M. Retuerce (eds.), Cerámicas tardorromanas y altomedievales en la península ibérica: ruptura y continuidad, II Simposio de Arqueología, Anejos de Archivo Español de Arqueología XXVIII, Madrid, 371-388.

Vigil-Escalera, A. 2006a: "La cerámica del período visigodo en Madrid”, J. Morín de Pablos (ed.), La investigación arqueológica de la época visigoda en la comunidad de Madrid. Vol. III. La cultura material, Zona Arqueológica 8, Alcalá de Henares, 729-737.

Vigil-Escalera, A. 2006b: "Aspectos sobre la cultura material en Hispania (Ss. V - VII). Problemas de visibilidad / invisibilidad del registro arqueológico", J. López Quiroga, A. M. Martínez Tejera y J. Morín de Pablos (eds.), Gallia e Hispania en el contexto de la presencia "germánica" (ss. V-VII). Balances y perspectivas, BAR International Series 1534, Oxford, 89-108.

Vigil-Escalera, A. 2007: "Algunas observaciones sobre las cerámicas de 'época visigoda' (ss. V - IX d.C.) de la región de Madrid”, A. Malpica y J. C. Carvajal (eds.), Estudios de Cerámica Tardorromana y Altomedieval, Granada, 371-394.

Vigil-Escalera, A. y Quirós, J. A. 2012: “Arqueología de los paisajes rurales altomedievales en el noroes- te peninsular", L. Caballero, P. Mateos y T. Cordero (eds.), Visigodos y omeyas: el territorio, Anejos del Archivo Español de Arqueología LXI, Mérida, 79-95.

Vigil-Escalera, A. y Quirós, J. A. (eds.) 2016: La cerámica de la Alta Edad Media en el cuadrante noroeste de la península ibérica (siglos $V$-X). Sistemas de producción, mecanismos de distribución y patrones de consumo, Bilbao.

Whitbread, I. K. 1989: "A proposal for the systematic description of thin sections towards the study of ancient ceramic technology", Y. Maniatis (ed.), Archaeometry. Proceedings of the 25th international symposium, Amsterdam, 127-138.

Whitbread, I. K. 1995: Greek transport amphorae, a petrological and archaeological study. Fitch Laboratory Occasional Paper, 4, Atenas.

Whitbread, I. K. 2001: "Ceramic Petrology, Clay Geochemistry and Ceramic Production. From Technology to the Mind of the Potter", D. R. Brothwell, A. M. Pollard (eds.), Handbook of Archaeological Sciences, Michigan, 449-458.

Wickham, C. 2009: The inheritance of Rome. A History of Europe from 400 to 1000, London.

Recibido: 18-03-2019

Aceptado: 11-04-2019 
